\title{
Article \\ Solvent-Induced Polymorphism of Iron(II) Spin Crossover Complexes
}

\author{
Ivan Šalitroš ${ }^{1,2, *}$, Olaf Fuhr ${ }^{1,3}$ and Mario Ruben ${ }^{1,4, *}$ \\ 1 Institut für Nanotechnologie, Karlsruher Institut für Technologie, Postfach 3640, Karlsruhe 76021, Germany; \\ olaf.fuhr@kit.edu \\ 2 Faculty of Chemical and Food Technology, Institute of Inorganic Chemistry, Technology and Materials, \\ Slovak University of Technology, Bratislava 812 37, Slovakia \\ 3 Karlsruhe Nano Micro Facility (KNMF), Karlsruher Institut für Technologie, Postfach 3640, \\ Karlsruhe 76021, Germany \\ 4 Institute de Physique et Chimie de Matériaux de Strasbourg (IPCMS), CNRS-Université de Strasbourg, \\ 23, rue du Loess BP 43, F-67034 Strasbourg cedex 2, France \\ * Correspondence: ivan.salitros@stuba.sk (I.Š.); mario.ruben@kit.edu (M.R.); \\ Tel.: +421-908-845-320 (I.Š. \& M.R.)
}

Academic Editor: Wolfgang Linert

Received: 30 June 2016; Accepted: 14 July 2016; Published: 19 July 2016

\begin{abstract}
Two new mononuclear iron(II) compounds (1) and (2) of the general formula $\left[\mathrm{Fe}(\mathbf{L})_{2}\right]\left(\mathrm{BF}_{4}\right)_{2} \cdot \mathrm{nCH}_{3} \mathrm{CN}$ ( $\mathbf{L}=4$-(2-bromoethyn-1-yl)-2,6-bis(pyrazol-1-yl)pyridine, $n=1$ for (1) and $n=2$ for compound (2)), were synthesized. The room temperature crystallization afforded concomitant formation of two different solvent analogues: compound (1) exhibiting triclinic P-1 and compound (2) monoclinic C2/c symmetry. Single-crystal X-ray studies confirmed the presence of the LS (low-spin) state for both compounds at $180 \mathrm{~K}$ and of the HS (high-spin) state for compound (2) at $293 \mathrm{~K}$, in full agreement with the magnetic investigations for both solvent polymorphs. Compound (1) exhibits spin transition above $293 \mathrm{~K}$ followed by subsequent solvent liberation, while the spin transition of (2) takes already place at $237 \mathrm{~K}$. After complete solvent removal from the crystal lattice, compound (1d) (the desolvated polymorph derived from (1)) exhibits spin transition centered at $342 \mathrm{~K}$ accompanied by a thermal hysteresis loop, while the analogous compound (2d) (the desolvated derivate of compound (2)) remains blocked in the HS state over all the investigated temperature range.
\end{abstract}

Keywords: spin crossover; iron(II) complexes; molecular magnetism; polymorphism

\section{Introduction}

Spin crossover (SCO) can be considered as a unimolecular transformation upon which switching entities (e.g., molecular complexes or coordination polymers) are reversibly transformed between the low-spin (LS) and high-spin (HS) state. The transition of spin states is an entropy-driven process, which can be triggered by external parameters such as temperature [1], pressure [2], magnetic [3] or electric field [4,5], and by irradiation with the visible/near-infrared [6] or even X-ray [7] range. Up to now, the occurrence of the SCO phenomenon was observed for central atoms in coordination compounds of $3 \mathbf{d}^{4}-3 \mathbf{d}^{7}$ electronic configuration, whereby the spherical symmetry of $d$-orbitals was broken into the $e_{g}$ and $t_{2 g}$ orbital subsets by the tetragonal bipyramidal environment of the $\mathrm{N}_{6}$ coordination environment. From the thermodynamic point of view, the SCO can be described as a case of electronic bistability, which is associated with the existence of two minima of the Gibbs energy [8]. The LS state minimum holds the occupation of electrons according to the Aufbau principle, whereas the HS state minimum possesses an electronic configuration according to the Hund's rule of maximal multiplicity. The separation between the reference states is proportional to the ligand field strength of $10 \mathrm{Dq}$. When the 
energy difference between the HS and LS states is of the order of $k_{\mathrm{B}} T$ (where $T$ is the temperature and $k_{\mathrm{B}}$ is the Boltzmann constant), switching between spin states on a molecular level can be stimulated by the change of temperature.

However, on the macroscopic scale, partially due to the extremely small energy differences, the ST is a highly subtle phenomenon, which can be easily affected by miscellaneous chemical [9] and/or structural $[10,11]$ factors. The investigation of the environmental influences allows for tuning of the SCO parameters by, e.g., controlling the presence of solvent molecules in the crystal lattice [12]. In such way, the properties of SCO materials, requested to fulfill technological criteria such as abruptness, hysteresis and room-temperature transition [13] can be deliberately tailored. The technological advanced family of iron(II)-triazole [14] complexes and iron(II)-pyrazine-tetracyanometalate [15] networks are positive examples for such a molecular engineering approach. Beyond SCO coordination polymers, discrete molecular SCO species incorporating imidazole- [16], pyrazole- [17] or pyridine-type [18-20] ligands have been shown to exhibit room temperature transitions with moderate thermal hysteresis widths [21]. Within the last decade, the iron(II) complexes with tridentate bis(pyrazole)pyridine [22-33] ligands have drawn increasing of attention to the field of SCO complexes. It has been shown that the modification of the ligand skeleton by substituents on the pyridine [23-26] or pyrazole [27] moiety leads to a fine-tuning of SCO properties. This is in fact a powerful tool for the synthesis of room temperature SCO compounds with anchoring functional substituents, which are tailor-made for the fabrication of hybrid materials, i.e., SCO surfaces [28] or SCO nanoparticles [29]. With respect to this, also halogen substituents might significantly support the cooperativity effect via non-covalent interactions [29] as well as increase the ligand field strength and elevate the $\mathrm{T}_{1 / 2}$ temperature [27]. Another chemical factor affecting the SCO parameters is presence of the hosts, i.e., solvent molecules in the crystal lattice. The solvation/desolvation processes can actively change the transition behavior [31-33]. In this sense, the detailed study and understanding of the substituent effect and solvent-driven spin and phase transitions is one of the pivotal challenges for the SCO investigation.

Herein, we report on the synthesis, structural and magnetic investigation of two iron(II) SCO complexes (1) and (2), both containing the tridentate bis(pyrazol-1-yl)pyridine type of ligands. The coordination compound of the general formula $\left[\mathrm{Fe}(\mathbf{L})_{2}\right]\left(\mathrm{BF}_{4}\right)_{2}(\mathbf{L}=4$-(2-bromoethyn-1-yl)-2,6bis(pyrazol-1-yl)pyridine) exists in two different solvated and structural forms which differ in the number of acetonitrile molecules. Magnetic studies reveal that SCO is present in both solvent analogues (1) and (2). In situ solvent liberation within the magnetic measurements results in two different polymorphs of solvent-free compound $\left[\mathrm{Fe}(\mathbf{L})_{2}\right]\left(\mathrm{BF}_{4}\right)_{2}$ and magnetic investigation allowed us to recognize that compound (1d) (the desolvated polymorph derived from (1)) shows SCO centered at $T_{1 / 2}=342 \mathrm{~K}$ and compound (2d) (the desolvated polymorph derived from (2)) persists in the HS state over the whole investigated temperature range.

\section{Results and Discussion}

\subsection{Synthesis, Crystallization and Thermogravimetry Analysis}

The tridentate ligand L, 4-(2-bromoethyn-1-yl)-2,6-bis(pyrazol-1-yl)pyridine, was obtained as a white powder in almost quantitative yield via reaction of 4-ethynyl-2,6-bis(pyrazol-1-yl)pyridine [24-26] with $\mathrm{N}$-bromosuccinimide, catalyzed by $\mathrm{AgNO}_{3}$ in acetone solvent. In the next step, ligand $\mathbf{L}$ was coordinated by the $\mathrm{Fe}\left(\mathrm{BF}_{4}\right)_{2} \cdot 6 \mathrm{H}_{2} \mathrm{O}$ salt. The crystallization from the acetonitrile solution yielded two different compounds: (1) with the general formula $\left[\mathrm{Fe}(\mathbf{L})_{2}\right]\left(\mathrm{BF}_{4}\right)_{2} \cdot \mathrm{CH}_{3} \mathrm{CN}$ and (2) with formula $\left[\mathrm{Fe}(\mathrm{L})_{2}\right]\left(\mathrm{BF}_{4}\right)_{2} \cdot 2 \mathrm{CH}_{3} \mathrm{CN}$. Due to the small size and similarity of the single crystals, separation of the two different solvent crystals was not successful.

Thermogravimetry analysis of the unknown mixture of (1) and (2) was performed at ambient pressure. The first decrease of about $5 \%$ of mass around $100{ }^{\circ} \mathrm{C}$ (Figure 1) is attributed to the release of acetonitrile molecules from the crystal lattice. Solvent-free compounds (1d) and (2d), derived from their solvated analogues, are remarkably stable up to $200{ }^{\circ} \mathrm{C}$, and begin to decompose above this 
temperature. The fact that respective acetonitrile solvent molecules did not escape at their boiling point during the thermogravimetric measurements indicates a significant interaction of these species with the complex molecule through supramolecular bonds.

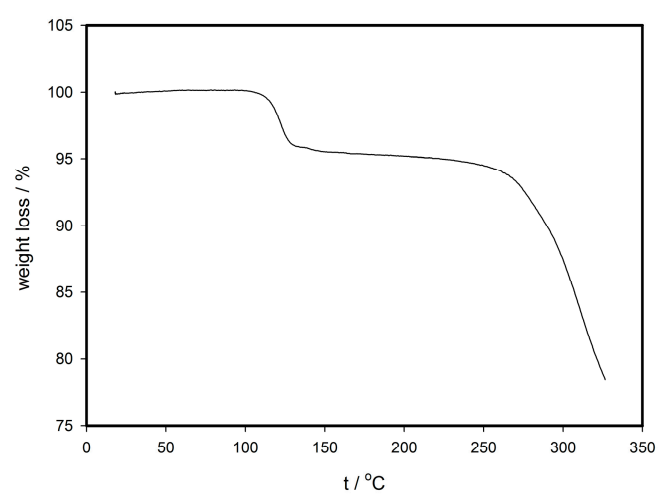

Figure 1. Thermogram of mixture sample of compounds (1) and (2).

\subsection{Structural Investigation}

At $180 \mathrm{~K}$, the single-crystal X-ray diffraction study of (1) (Figure 2a) reveals a triclinic space group $P-1$ exhibiting a unit cell volume of $\mathrm{V}=1713.9(6) \AA^{3}$ and lattice parameters of $a=11.324(2) \AA$, $b=11.742(2) \AA, c=14.187(3) \AA, \alpha=83.29(3)^{\circ}, \beta=84.40(3)^{\circ}, \gamma=66.38(3)^{\circ}$ (Table 1). The asymmetric unit of (1) contains one complex $\left[\mathrm{Fe}(\mathbf{L})_{2}\right]^{2+}$, two corresponding $\mathrm{BF}_{4}{ }^{-}$counter anions and one $\mathrm{CH}_{3} \mathrm{CN}$ solvent molecule. Two molecular species of formula $\left[\mathrm{Fe}(\mathrm{L})_{2}\right]\left(\mathrm{BF}_{4}\right)_{2} \cdot \mathrm{CH}_{3} \mathrm{CN}$ are present in the unit cell. At the temperature of the measurement, the Fe-N distances are in the range 1.887(3)-1.973(3) $\AA$, indicating the iron(II) LS state (Table 2).

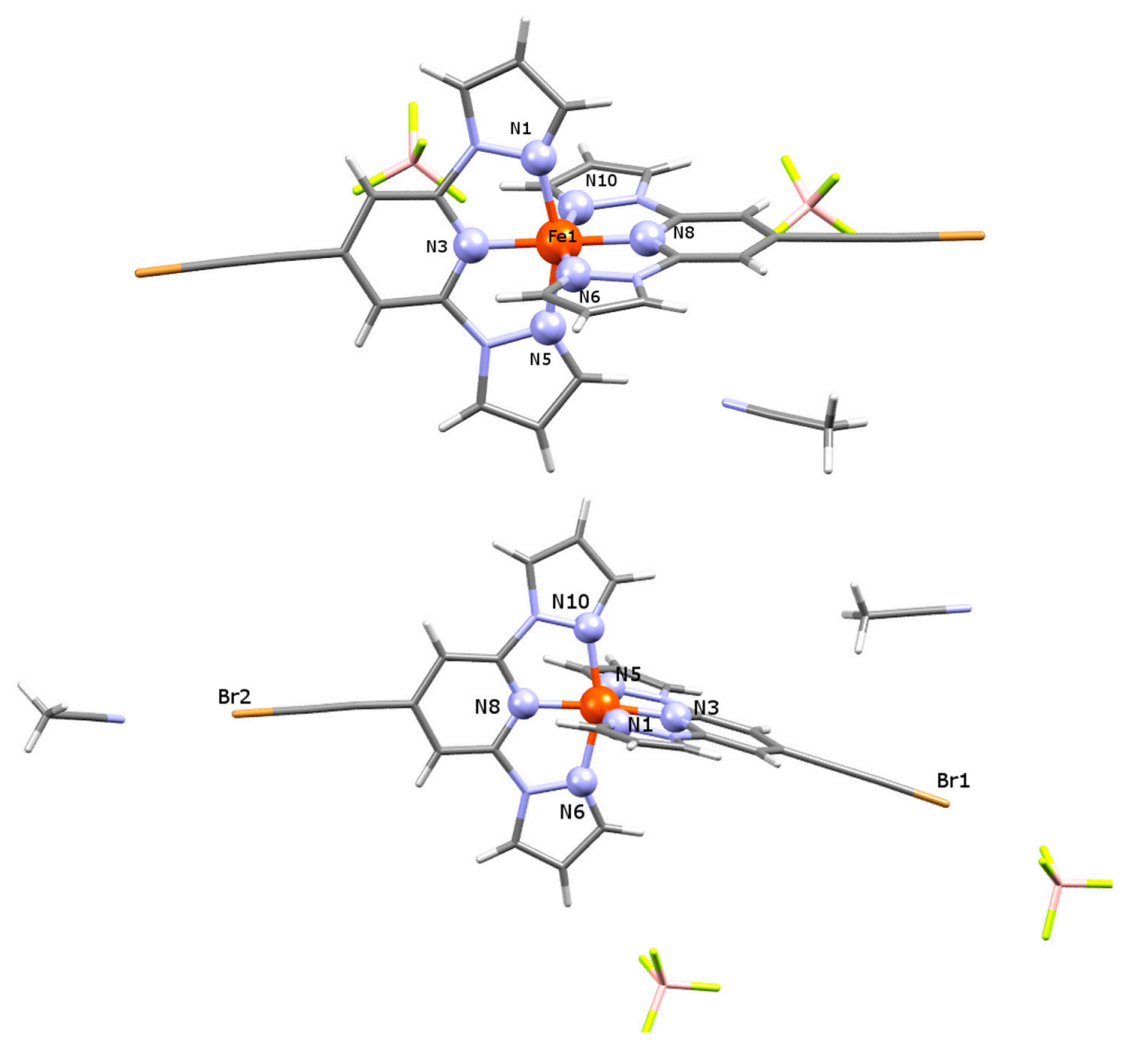

(a)

(b)

Figure 2. Asymmetric unit of solvated analogues (a) (1) and (b) (2). 
Table 1. Crystal structure parameters for compounds (1) and (2).

\begin{tabular}{|c|c|c|c|}
\hline & $\begin{array}{c}\text { Compound (1) } \\
{\left[\mathrm{Fe}(\mathrm{L})_{2}\right]\left(\mathrm{BF}_{4}\right)_{2} \cdot \mathrm{CH}_{3} \mathrm{CN}}\end{array}$ & $\begin{array}{r}\text { Comp } \\
{\left[\mathrm{Fe}(\mathrm{L})_{2}\right](\mathrm{BI}}\end{array}$ & $\begin{array}{l}\text { Ind (2) } \\
2 \cdot 2 \mathrm{CH}_{3} \mathrm{CN}\end{array}$ \\
\hline Formula & $\mathrm{C}_{28} \mathrm{H}_{19} \mathrm{~B}_{2} \mathrm{Br}_{2} \mathrm{~F}_{8} \mathrm{FeN}_{11}$ & $\mathrm{C}_{30} \mathrm{H}_{22} \mathrm{~B}_{2} \mathrm{Br}_{2} \mathrm{~F}_{8} \mathrm{FeN}_{12}$ & $\mathrm{C}_{30} \mathrm{H}_{22} \mathrm{~B}_{2} \mathrm{Br}_{2} \mathrm{~F}_{8} \mathrm{FeN}_{12}$ \\
\hline Formula weight $/ \mathrm{g} \cdot \mathrm{mol}^{-1}$ & 898.83 & 939.89 & 939.89 \\
\hline Crystal color & Red & orange & orange \\
\hline Temperature/K & $180(2)$ & $180(2)$ & $293(2)$ \\
\hline Wavelength/ & 0.71073 & 0.71073 & 0.71073 \\
\hline Crystal system & Triclinic & monoclinic & monoclinic \\
\hline Space group & $P-1$ & $\mathrm{C} 2 / \mathrm{c}$ & $\mathrm{C} 2 / \mathrm{c}$ \\
\hline$a / \AA$ & $11.324(2)$ & $24.948(5)$ & $25.311(5)$ \\
\hline$b / \AA$ & $11.742(2)$ & $20.260(4)$ & $20.702(4)$ \\
\hline$c / \AA$ & $14.187(3)$ & $18.360(4)$ & $18.395(4)$ \\
\hline$\alpha /^{\circ}$ & $83.29(3)$ & 90.00 & 90.00 \\
\hline$\beta /{ }^{\circ}$ & $84.40(3)$ & $129.92(3)$ & $129.81(3)$ \\
\hline$\gamma /{ }^{\circ}$ & $66.38(3)$ & 90.00 & 90.00 \\
\hline $\mathrm{V} / \AA^{3}$ & $1713.9(6)$ & $7117(3)$ & 7404(3) \\
\hline$Z, \rho_{\text {calc }} / \mathrm{g} \cdot \mathrm{cm}^{-3}$ & $2,1.742$ & $8,1.754$ & $8,1.686$ \\
\hline$\mu\left(\mathrm{Mo}-\mathrm{K}_{\alpha}\right) / \mathrm{mm}^{-1}$ & 2.855 & 2.755 & 2.648 \\
\hline$F(000)$ & 884 & 3712 & 3712 \\
\hline Crystal size/mm & $0.35 \times 0.33 \times 0.16$ & $0.41 \times 0.32 \times 0.24$ & $0.41 \times 0.32 \times 0.24$ \\
\hline $\begin{array}{l}\theta \text { range for the data } \\
\text { collection } /{ }^{\circ}\end{array}$ & 1.45 to 25.64 & 1.46 to 25.62 & 1.34 to 25.79 \\
\hline Final $R$ indices $[I>2 \sigma(\mathrm{I})]$ * & $\begin{array}{c}R_{1}=0.0371 \\
w R_{2}=0.0929\end{array}$ & $\begin{array}{c}R_{1}=0.0375 \\
w R_{2}=0.0852\end{array}$ & $\begin{array}{c}R_{1}=0.0516 \\
w R_{2}=0.1314\end{array}$ \\
\hline$R$ indices (all data) * & $\begin{array}{c}R_{1}=0.0453 \\
w R_{2}=0.0964\end{array}$ & $\begin{array}{c}R_{1}=0.0525 \\
w R_{2}=0.0902\end{array}$ & $\begin{array}{c}R_{1}=0.0707 \\
w R_{2}=0.1417\end{array}$ \\
\hline GoF on $F^{2}$ & 1.046 & 1.048 & 1.035 \\
\hline CCDC deposit number & 846337 & 846338 & 846339 \\
\hline
\end{tabular}

${ }^{*} R_{1}=\sum\left(F_{0}-F_{c}\right) / \sum F_{0} ; w R_{2}=\sqrt{\frac{\sum\left[w\left(F_{0}^{2}-F_{c}^{2}\right)\right]}{\sum\left[w\left(F_{0}^{2}\right)^{2}\right]}}$.

Table 2. Fe-N bond distances (in $\AA$ ) for (1) and (2).

\begin{tabular}{|c|c|c|}
\hline $\begin{array}{c}(1) \\
180(2) \mathrm{K}\end{array}$ & $\begin{array}{c}(2) \\
180(2) \mathrm{K}\end{array}$ & $\begin{array}{c}(2) \\
293(2) \mathrm{K}\end{array}$ \\
\hline Fe1-N1 = 1.973(2) & Fe1-N1 = 1.971(3) & $\mathrm{Fe} 1-\mathrm{N} 1=2.133(4)$ \\
\hline Fe1-N3 = 1.887(2) & Fe1-N3 = 1.906(3) & $\mathrm{Fe} 1-\mathrm{N} 3=2.104(3)$ \\
\hline Fe1-N5 = 1.972(2) & Fe1-N5 = 1.981(3) & Fe1-N5 = 2.151(4) \\
\hline Fe1-N6 = 1.973(3) & Fe1-N6 =1.981(3) & Fe1-N6 = 2.173(4) \\
\hline Fe1-N8 = 1.895(2) & Fe1-N8 = 1.900(3) & Fe1-N8 = 2.098(3) \\
\hline Fe1-N10 = 1.962(2) & Fe1-N10 = 1.998(3) & $\mathrm{Fe} 1-\mathrm{N} 10=2.160(4)$ \\
\hline $\mathrm{N}_{\mathrm{pz}}-\mathrm{Fe}-\mathrm{N}_{\mathrm{py}}{ }^{*}=80.1$ & $\mathrm{~N}_{\mathrm{pz}}-\mathrm{Fe}-\mathrm{N}_{\mathrm{py}}=79.9$ & $\mathrm{~N}_{\mathrm{pz}}-\mathrm{Fe}-\mathrm{N}_{\mathrm{py}}=74.1$ \\
\hline N3-Fe-Fe8 = 179.3 & N3-Fe-Fe8 = 173.0 & N3-Fe-Fe8 = 167.7 \\
\hline
\end{tabular}

In order to investigate structural changes upon SCO (vide infra), the single-crystal X-ray structure of compound (2) was determined at $180 \mathrm{~K}$ (LS state) and at $293 \mathrm{~K}$ (HS state) using the same single crystal (Figure $2 b$ ). At both temperatures, the diffraction study elucidates a monoclinic system with $C 2 / c$ symmetry, where the asymmetric unit contains one cationic complex $\left[\mathrm{Fe}(\mathbf{L})_{2}\right]^{2+}$, two disordered $\mathrm{BF}_{4}{ }^{-}$counter anions and two acetonitrile molecules. Unit cell parameters and other selected structural information are listed in Table 1. Coming from the LS to HS state, the unit cell volume increases about $4 \%$, lattice parameters of $a$ increase $1.5 \%$ and those of $b$ increase $2.2 \%$, respectively. The low temperature bond distances of a coordination polyhedron vary in the range 1.900(3)-1.998(3) $\AA$ and, 
likewise for (1), they indicate the LS state of the central atom. At $293 \mathrm{~K}, \mathrm{Fe}-\mathrm{N}$ lengths acquire values typical for the HS state of the central atom (2.098(3)-2.173(3) $\AA$, Table 2) and in comparison to the LS structure, the most significant increase of distances is observed for the axial Fe1-N3 and Fe1-N8 bonds $(\approx 10.4 \%)$, which are placed along the $b$ direction. The equatorial Fe1-N6 and Fe1-N10 bonds situated along the $a b$ plane show a variation between LS and HS distances of about $9.7 \%$ and $8.1 \%$, and the third bond-couple Fe1-N1 and Fe1-N5 placed along the $b c$ plane increases about $8.2 \%$ and $8.6 \%$, respectively.

The shape of coordination polyhedra of all three structures is a strongly deformed tetragonal bipyramid, whereby its plasticity can be expressed by the $\Sigma$ parameter [34,35]. The LS $\Sigma$ values $85.6^{\circ}$ for $(\mathbf{1})$ and $89.0^{\circ}$ for (2), respectively, are significantly lower than that for the room temperature structure of $(2)\left(\Sigma=146.0^{\circ}\right)$. Also, so-called bite angles $\left(\mathrm{N}_{\mathrm{pz}}-\mathrm{Fe}-\mathrm{N}_{\mathrm{py}}\right.$, Table 2$)$ are good "indicators" for the change of the spin state in the family of bis(pyrazol-1-yl)pyridine-iron(II) compounds [9-11]. So the LS structures of (1) and (2) indicate values of $80.1^{\circ}$ and $80.0^{\circ}$, respectively, while the HS value of compound (2) (at $293 \mathrm{~K}$ ) with $74.1^{\circ}$ is significantly smaller. The Jahn-Teller distortion of HS iron(II) molecules can be expressed also by the angle $\mathrm{N}_{\mathrm{py}}-\mathrm{Fe}-\mathrm{N}_{\mathrm{py}}$, which is straight for (1) and (2) at $180 \mathrm{~K}$ but significantly bent at room temperature for (2) (Table 2). The detailed look into the monoclinic structure of (2) reveals short contacts between the endstanding bromine atoms of the $\mathbf{L}$ ligand with the acetonitrile nitrogen atoms on the one side of the molecule (2.9998(5) $\AA$ at $293 \mathrm{~K}, 2.9375(44) \AA$ at $180 \mathrm{~K})$, and with the $\mathrm{BF}_{4}{ }^{-}$counter anion fluorine atoms $(2.8342(61) \AA$ at $293 \mathrm{~K}, 2.8375(6) \AA$ at $180 \mathrm{~K}$ ) on the other side of the molecule (Figure $2 \mathrm{~b}$ ). At $180 \mathrm{~K}$, both structures show weak interactions between the ligand atoms and $\mathrm{BF}_{4}{ }^{-}$counter anions. Those weak hydrogen binding and $\mathrm{F} \cdots \mathrm{H}-\mathrm{C}$ contacts are shorter than sum of the van der Waals radii of $\mathrm{F}$ and $\mathrm{H}(2.55 \AA)$ [36] and vary in the range of 3.1251(37)-3.3650(41) $\AA$ (with corresponding angles from $121.2(2)^{\circ}$ to $170.4(2)^{\circ}$ ) for $(1)$, and 3.1241(77)-3.3080(76) $\AA$ (with corresponding angles from $126.9(3)^{\circ}$ to $162.4(2)^{\circ}$ ) for (2), respectively (see Supplementary Materials S1). For compound (2), neither the SCO nor the increases of temperature have a significant impact on the prolongation of the non-covalent interactions. Furthermore, the thermochromism related to SCO processes was investigated for single crystals of (2), whereby the initial dark orange changed gradually to light orange without losing its crystallinity (Figure 3).

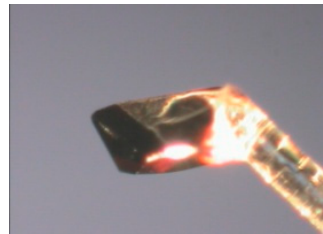

$200 \mathrm{~K}$

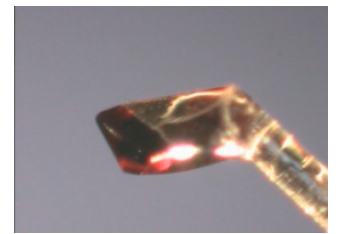

$250 \mathrm{~K}$

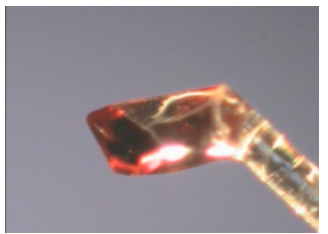

$270 \mathrm{~K}$

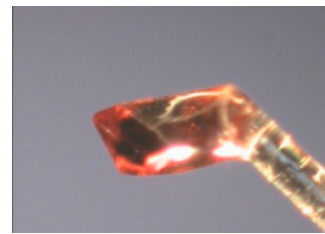

$293 \mathrm{~K}$

Figure 3. (Color on-line) Representation of the thermochromism of compound 2.

\subsection{Magnetic Properties of Compounds (1) and (2)}

The high similarity of the crystals of (1) and (2) impeded a clean separation in order to separately investigate their magnetic properties. Therefore, we decided to study a sample of an unknown ratio of both compounds (1) $\left(\left[\mathrm{Fe}(\mathrm{L})_{2}\right]\left(\mathrm{BF}_{4}\right)_{2} \cdot \mathrm{CH}_{3} \mathrm{CN}\right)$ and (2) $\left(\left[\mathrm{Fe}(\mathrm{L})_{2}\right]\left(\mathrm{BF}_{4}\right)_{2} \cdot 2 \mathrm{CH}_{3} \mathrm{CN}\right)$, drawing conclusions inductively on the individual magnetic properties from the observed overall magnetic and crystallographic properties. According to the results from X-ray diffraction studies, both compounds are in LS state at $180 \mathrm{~K}$, which is in good agreement with the variable temperature magnetic investigation of the (1)/(2) mixture (Figure 4a, red circles). Below $200 \mathrm{~K}$, the product function of the measured sample acquires positive values close to zero, which can be explained by the small presence of paramagnetic impurities. Above $200 \mathrm{~K}$, however, the sample exhibits an increase of the product function and reaches a plateau at room temperature. Keeping in mind that the room temperature bond distances of (2) indicate the HS state (vide supra), it can be concluded that the first spin crossover placed around $237 \mathrm{~K}$ belongs to compound (2). The $\chi T$ product reaches $0.51 \mathrm{~cm}^{3} \cdot \mathrm{K} \cdot \mathrm{mol}^{-1}$ at $290 \mathrm{~K}$, 
which corresponds to a ratio of $17 \%$ of HS iron(II). Upon further warming above room temperature, the second spin crossover takes place. However, it is accompanied with the liberation of acetonitrile lattice solvent molecules. At $380 \mathrm{~K}$, the $\chi T$ function reaches $2.9 \mathrm{~cm}^{3} \cdot \mathrm{K} \cdot \mathrm{mol}^{-1}$ which is very close to the expected value for the HS state of Fe(II); however, the SCO curve is not saturated yet. The loss of solvent molecules from crystal structures of (1) and (2) has created two polymorphic forms (1d) and (2d) of compound $\left[\mathrm{Fe}(\mathbf{L})_{2}\right]\left(\mathrm{BF}_{4}\right)_{2}$. The magnetic data of the desolvated sample (Figure 4a; blue circles) indicate a gradual spin crossover centered around $342 \mathrm{~K}$. Moreover, the SCO is accompanied by a hysteresis loop, which is constant during all three heating cycles (see Supplementary Materials S2). Below $293 \mathrm{~K}$, the SCO reaches the LS plateau at $0.5 \mathrm{~cm}^{3} \cdot \mathrm{mol}^{-1} \cdot \mathrm{K}$ (at $100 \mathrm{~K}$ ) which corresponds to $17 \%$ of the HS mole fraction. The field dependency of molar magnetization of the desolvated mixture was carried out at $1.9 \mathrm{~K}$ (Figure $4 \mathrm{~b}$ ), whereby the saturation of $M_{\mathrm{mol}}$ is achieved around $0.6 \mu_{\mathrm{B}}$ at $5 \mathrm{~T}$ which deviates around $15 \%$ from the expected value for the HS mononuclear iron(II) compounds $(S=2)$.

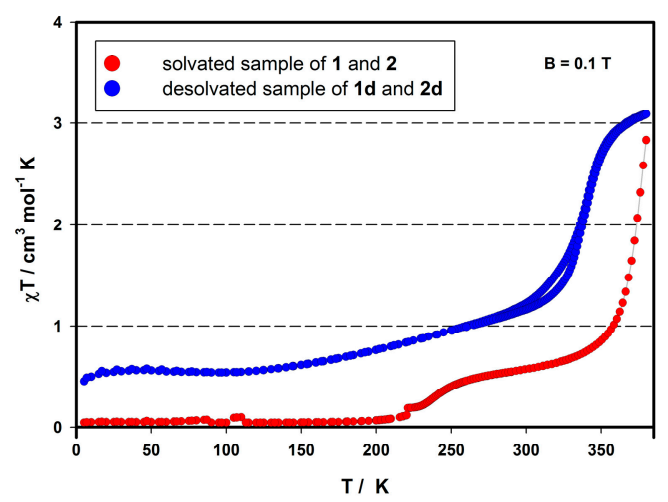

(a)

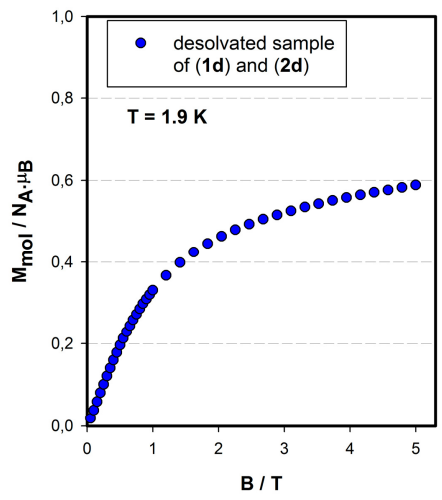

(b)

Figure 4. (a) Temperature-dependent magnetic properties of solvated (red circles) and desolvated (blue circles) mixture of compounds (1) $\left[\mathrm{Fe}(\mathrm{L})_{2}\right]\left(\mathrm{BF}_{4}\right)_{2} \cdot \mathrm{CH}_{3} \mathrm{CN}$ and (2) $\left[\mathrm{Fe}(\mathbf{L})_{2}\right]\left(\mathrm{BF}_{4}\right)_{2} \cdot 2 \mathrm{CH}_{3} \mathrm{CN}$; (b) Field-dependent mole magnetization of desolvated sample at $1.9 \mathrm{~K}$ (mixture of (1d) and (2d)).

On the grounds of the obtained results-(i) $17 \%$ of HS iron(II) observed at $293 \mathrm{~K}$ in the pristine sample; (ii) $17 \%$ of remnant HS fraction observed after desolvation; and (iii) $15 \%$ of HS iron(II) found according to the $M_{\mathrm{B}}$ vs. $B$ measurement in the desolvated $(\mathbf{1 d}) /(\mathbf{2 d})$ sample-it can be concluded that the remnant HS molar fraction of the desolvated sample can exclusively come from the desolvated (2d) polymorph, while the above-room-temperature SCO behavior is due to the (1d) polymorph. In other words, it can be noticed that compound (1) $\left[\mathrm{Fe}(\mathrm{L})_{2}\right]\left(\mathrm{BF}_{4}\right)_{2} \cdot \mathrm{CH}_{3} \mathrm{CN}$ possesses LS diamagnetic behavior up to room temperature, but releases acetonitrile solvent molecules above $300 \mathrm{~K}$, subsequently leading to the SCO effect accompanied by a thermal hysteresis loop. On the other hand, compound (2) $\left[\mathrm{Fe}(\mathrm{L})_{2}\right]\left(\mathrm{BF}_{4}\right)_{2} \cdot 2 \mathrm{CH}_{3} \mathrm{CN}$ exhibits a SCO centered at $237 \mathrm{~K}$ and looses acetonitrile solvent molecules at elevated temperatures to subsequently stay blocked in the HS.

\section{Materials and Methods}

\subsection{General}

Purchased chemicals (N-Bromosuccinimide, $\mathrm{Fe}\left(\mathrm{BF}_{4}\right)_{2} \cdot 6 \mathrm{H}_{2} \mathrm{O}, \mathrm{AgNO} \mathrm{NO}_{3}$ ) were used as received. The compound 4-ethynyl-2,6-bis(pyrazol-1-yl)pyridine was prepared as described previously $[25,26]$. Acetone, hexane, ethyl acetate, acetonitrile and diethyl ether solvents were used without any further purification. Elemental analyses of carbon, hydrogen, and nitrogen were carried out by Vario Micro Cube. FT IR spectra were measured in KBr pellets (Magna FTIR 750, Nicolet, INT KIT, Karlsruhe, Germany in the $4000-400 \mathrm{~cm}^{-1}$ region. ${ }^{1} \mathrm{H}$ and ${ }^{13} \mathrm{C}$ NMR spectra were recorded in a Bruker DPX 300 spectrometer INT KIT, Karlsruhe, Germany) with solvent proton and carbon atoms 
as an internal standard. Matrix-assisted laser desorption/ionization time of flight (MALDI-TOF, INT KIT, Karlsruhe, Germany) mass spectrometric analytical data were acquired on a Voyager-DE PRO Bio spectrometry workstation (INT KIT, Karlsruhe, Germany). Electro-spray ionization time of flight (ESI-TOF) mass spectrometric analytical data were acquired on a microOTOF-Q II Bruker (INT KIT, Karlsruhe, Germany). Thermogravimetric analysis (TG) was performed in a He flow at a heating rate of $2.5 \mathrm{~K} \cdot \mathrm{min}^{-1}$ in a Netzsch STA $409 \mathrm{C}$ analyzer (INT KIT, Karlsruhe, Germany).

\subsection{Synthesis}

The compound 4-ethynyl-2,6-bis(pyrazol-1-yl)pyridine was prepared according a reported procedure [26,27] via Sonoghashira coupling reaction of 4-iodo-2,6-bis(pyrazol-1yl)pyridine [24,25] with trimethylsilylacethylene in the first synthetic step and following deprotection of trimethylsilyl protecting group with methanol and sodium carbonate in the second step. The ligand preparation resulted in $79 \%$ yield as a white powder.

4-(2-bromoethyn-1-yl)-2,6-bis(pyrazol-1-yl)pyridine (L): $1 \mathrm{~g}$ (4.25 mmol) of 4-ethynyl-2,6bis(pyrazol-1-yl)pyridine was dissolved in $100 \mathrm{~cm}^{3}$ of acetone, then $0.83 \mathrm{~g}(8.5 \mathrm{mmol})$ of $\mathrm{N}$-bromosuccinimide and $60 \mathrm{mg}(0.35 \mathrm{mmol})$ of $\mathrm{AgNO}_{3}$ were added. The resulted reaction mixture was stirred for $10 \mathrm{~h}$ under a $\mathrm{N}_{2}$ atmosphere at room temperature. The solvent was removed under vacuum using rotary evaporator and the resulting product was filtered on aluminium oxide with n-hexane/ethyl acetate $\left(10: 1 ; R_{\mathrm{f}}=0.64\right)$ as eluent. Due to the light sensibility of this compound, all manipulations dealing with $\mathrm{L}$ ligand were carried out in dark. ${ }^{1} \mathrm{H} \mathrm{NMR}\left(300 \mathrm{MHz}, \mathrm{CDCl}_{3}, 25{ }^{\circ} \mathrm{C}\right.$, $\delta /$ ppm): 6.49 (td, 2H, pyrazole), 7.75 (dd, 2H, pyrazole), 7.87 (s, 2H, pyridine), 8.53 (d, 2H, pyrazole). ${ }^{13} \mathrm{C}$ NMR $\left(75 \mathrm{MHz}, \mathrm{CDCl}_{3}, 25^{\circ} \mathrm{C}, \delta / \mathrm{ppm}\right): 107.42,112.19,127.41,136.28,143.00,150.56$. MALDI-TOF MS: experiment: $m / z$ (relative intensity of isotopic distribution) $=314.14(100 \%), 315.13(18 \%), 316.13$ (95\%); 317.10 (15\%) simulation: $m / z$ (relative intensity of isotopic distribution) $=313.00(100 \%), 314.00$ (17\%), 316.13 (97\%); 317.10 (15\%). Elemental analysis for $\mathrm{C}_{13} \mathrm{H}_{8} \mathrm{~N}_{5} \mathrm{Br}$ (314.14): Found (Calc.): C 50.00 (49.70)\%; H 2.45(2.57)\%; N 21.92 (22.29)\%; yield $1.33 \mathrm{~g}(99 \%)$.

Synthesis of compounds $\left[\mathrm{Fe}(\mathrm{L})_{2}\right]\left(\mathrm{BF}_{4}\right)_{2} \cdot \mathrm{nCH}_{3} \mathrm{CN}(n=1,(\mathbf{1}) ; n=2(2))$ : An acetonitrile solution of $\mathrm{L}\left(0.1 \mathrm{~g}, 0.32 \mathrm{mmol}, 50 \mathrm{~cm}^{3}\right)$ was deoxygenated under the $\mathrm{N}_{2}$ flux, warmed-up to $60{ }^{\circ} \mathrm{C}$ and then a stoichiometric amount of $\mathrm{Fe}\left(\mathrm{BF}_{4}\right)_{2} \cdot 6 \mathrm{H}_{2} \mathrm{O}(0.054 \mathrm{~g}, 0.16 \mathrm{mmol})$ was added. The complexation of ligand $\mathbf{L}$ took place under color change to red-orange. The resulting reaction mixture was stirred at initial conditions $\left(60^{\circ} \mathrm{C}, \mathrm{N}_{2}\right.$ atmosphere) for $3 \mathrm{~h}$, cooled down to room temperature and filtered. Dark orange block-shaped crystals were grown from diffusing the diethyl ether into an acetonitrile solution of the complex under $\mathrm{N}_{2}$ at room temperature. The diffraction study of single crystals revealed concomitant formation of two different solvent analogues -compound (1) with the formula $\left[\mathrm{Fe}(\mathrm{L})_{2}\right]\left(\mathrm{BF}_{4}\right)_{2} \cdot \mathrm{CH}_{3} \mathrm{CN}$ and compound (2) of formula $\left[\mathrm{Fe}(\mathrm{L})_{2}\right]\left(\mathrm{BF}_{4}\right)_{2} \cdot 2 \mathrm{CH}_{3} \mathrm{CN}$. Unfortunately, the small size and similarity of single crystals did not allow for clean separation of compounds (1) and (2). As consequence, the mixture of the unknown ratio of those two solvent polymorphs was used for further analytical and physical property studies. Calc. for $\mathrm{C}_{28} \mathrm{H}_{19} \mathrm{~B}_{2} \mathrm{Br}_{2} \mathrm{~F}_{8} \mathrm{FeN}_{11}$ (898.75 g/mol) Found (Calc.): C 37.61 (37.42)\%; H $2.41(2.13) \%$; N 17.12 (17.14)\%. ESI-TOF MS: [Fe(L) $\left.)_{2}\right]^{2+}\left(\mathrm{FeC}_{26} \mathrm{H}_{16} \mathrm{Br}_{2} \mathrm{~N}_{10}\right)$ at $m / z=341.9681$ (calc. $\left.m / z=341.9624) ;\left[\mathrm{Fe}(\mathrm{L})_{2}\left(\mathrm{BF}_{4}\right)\right]^{+}\left(\mathrm{FeC}_{26} \mathrm{H}_{16} \mathrm{Br}_{2} \mathrm{~N}_{10} \mathrm{BF}_{4}\right)\right)$ at $m / z=770.9441$ (calc. $\left.m / z=770.9286\right)$; $\left[\mathrm{Fe}(\mathrm{L})_{2}\left(\mathrm{BF}_{4}\right)_{2}\right] \mathrm{Li}^{+}\left(\mathrm{FeC}_{26} \mathrm{H}_{16} \mathrm{Br}_{2} \mathrm{~N}_{10} \mathrm{~B}_{2} \mathrm{~F}_{8} \mathrm{Li}\right)$ at $m / z=864.8824$ (calc. $\left.m / z=864.9481\right)$. ${ }^{1} \mathrm{H} \mathrm{NMR}$ (300 MHz, $\mathrm{CH}_{3} \mathrm{CN}, 25^{\circ} \mathrm{C}, \delta / \mathrm{ppm}$ ): 56.82 (s, pyrazole), 52.01 (s, pyridine), 34.45 (pyrazole), 31.92 (s, pyrazole). FT IR (KBr; $\left.\bar{v} / \mathrm{cm}^{-1}\right)$ : $3155\left(\mathrm{~ms}, \mathrm{C}-\mathrm{H}_{\mathrm{ar}}\right), 3140\left(\mathrm{~ms}, \mathrm{C}-\mathrm{H}_{\mathrm{ar}}\right) ; 3133\left(\mathrm{~ms}, \mathrm{C}-\mathrm{H}_{\mathrm{ar}}\right), 3115$ (ms, $\left.\mathrm{C}-\mathrm{H}_{\mathrm{ar}}\right) ; 2205$ (ms, $\left.\mathrm{C} \equiv \mathrm{C}\right)$. Yield $0.10 \mathrm{~g}(71 \%)$.

\subsection{Magnetic Susceptibility Measurement}

All herein reported magnetic measurements were performed on a SQUID magnetometer (Quantum Design, model MPMS-XL-5, INT KIT, Karlsruhe, Germany). In all cases, the temperature dependence of the product function was recorded at $B=0.1 \mathrm{~T}$ as an external magnetic field. The temperature sweeping rate was $1 \mathrm{~K} \cdot \mathrm{min}^{-1}$ and was the same for cooling and heating mode. Gelatine 
capsules were used as sample containers for the measurement in the temperature range 5-380 K. Desolvation of (1) and (2) to (1d) and (2d) was obtained in situ within the magnetic measurement set-up. After first heating, three continuous cooling/heating cycles were applied until the last two measurements were identical. Thereby, the sample was maintained in the MPMS magnetometer at $380 \mathrm{~K}$ for $20 \mathrm{~min}$ before every cooling/heating cycle. The very small diamagnetic contribution of the gelatine capsule and high-temperature sample holder had a negligible contribution to the overall magnetization. The diamagnetic corrections of the molar magnetic susceptibilities were applied using Pascal's constants [9].

\subsection{Single-Crystal Diffraction}

Single-crystal X-ray diffraction data were collected on a STOE IPDS II diffractometer with graphite monochromated Mo K $\alpha$ radiation (0.71073 ̊̊). Structures were solved by direct methods (SHELX-97). Refinement was performed with anisotropic temperature factors for all non-hydrogen atoms (disordered atoms were refined isotropically) [37,38].

\section{Conclusions}

In conclusion, the results presented illustrate the effect of removal of auxiliary lattice solvent molecules as well as the influence of bromine substitution on the spin crossover. The solvent-induced polymorphism of the system $\left[\mathrm{Fe}(\mathrm{L})_{2}\right]\left(\mathrm{BF}_{4}\right)_{2} \cdot \mathrm{nCH}_{3} \mathrm{CN}$ was studied and $\mathrm{SCO}$ behavior dependent on host solvent molecules was observed. The polymorphs containing slightly different amounts of solvent molecules in the crystal lattice differ strongly in their magnetic properties, mostly due to the formation of different crystal lattice symmetries. However, after solvent removal, the magnetic behaviors of the desolvated samples also differ strongly in their properties. On the other hand, the introduction of bromo substituent onto the periphery of 4-ethynyl-2,6-bis(pyrazol-1-yl)pyridine significantly strengthens the intermolecular interactions between the complex cation and $\mathrm{BF}_{4}{ }^{-}$counter anions and/or solvent molecules. This type of interaction is missing in the case of "parental" iron(II) complexes with unsubstituted ligands [26,27], which is one of the reasons why related compounds exhibited such different spin crossover behavior. Our results highlight the importance of the control of the crystal lattice environment in ST materials, a problem to be taken into account in the design of molecular devices based on ST materials.

Supplementary Materials: The following are available online at www.mdpi.com/1996-1944/9/7/585/s1.

Acknowledgments: Grant Agencies (Slovakia: APVV-14-0078, APVV-14-0073, VEGA 1/0522/14, STU Grant scheme for Support of Excellent Teams of Young Researchers and COST Action CM1305 (ECOSTBio)) are acknowledged for their financial support.

Author Contributions: Ivan Šalitroš performed the synthesis and magnetic investigation; wrote the paper. Olaf Fuhr performed single-crystal X-ray diffraction experiments and Mario Ruben was the coordinator of the investigation.

Conflicts of Interest: The authors declare no conflict of interest. The founding sponsors had no role in the design of the study; in the collection, analyses, or interpretation of data; in the writing of the manuscript, and in the decision to publish the results.

\section{References and Note}

1. Nemec, I.; Herchel, R.; Boca, R.; Travnicek, Z.; Svoboda, I.; Fuess, H.; Linert, W. Tuning of spin crossover behaviour in iron(III) complexes involving pentadentate Schiff bases and pseudohalides. Dalton Trans. 2011, 40, 10090-10099. [CrossRef] [PubMed]

2. Ksenofontov, V.; Gaspar, A.B.; Gütlich, P. Pressure Effect Studies on Spin Crossover and Valence Tautomeric Systems. In Spin Crossover in Transition Metal Compounds III; Gütlich, P., Goodwin, H.A., Eds.; Springer-Verlag: Berlin/Heidelberg, Germany, 2004; ISSN: 0340-1022. 
3. Bousseksou, A.; Varret, F.; Goiran, M.; Boukheddaden, K.; Tuchagues, J.P. The Spin Crossover Phenomenon under High Magnetic Field. In Spin Crossover in Transition Metal Compounds III; Gütlich, P., Goodwin, H.A., Eds.; Springer-Verlag: Berlin/Heidelberg, Germany, 2004; ISSN: 0340-1022.

4. Meded, V.; Bagrets, A.; Fink, K.; Chandrasekar, R.; Ruben, M.; Evers, F.; Bernand-Mantel, A.; Seldenthuis, J.S.; Beukman, A.; van der Zant, H.S.J. Electrical control over the Fe(II) spin crossover in a single molecule: Theory and experiment. Phys. Rev. B 2011, 83, 245415. [CrossRef]

5. Prins, F.; Monrabal-Capilla, M.; Osorio, E.A.; Coronado, E.; van der Zant, H.S.J. Room-Temperature Electrical Addressing of a Bistable Spin-Crossover Molecular System. Adv. Mater. 2011, 23, 1545-1549. [CrossRef] [PubMed]

6. Hauser, A. Light-Induced Spin Crossover and the High-Spin $\rightarrow$ Low-Spin Relaxation. In Spin Crossover in Transition Metal Compounds II; Gütlich, P., Goodwin, H.A., Eds.; Springer-Verlag: Berlin/Heidelberg, Germany, 2004; ISSN: 0340-1022.

7. Collison, D.; Garner, C.D.; McGrath, C.M.; Mosselmans, J.F.W.; Roper, M.D.; Seddon, J.M.W.; Sinn, E.; Young, N.A. Soft X-ray induced excited spin state trapping and soft X-ray photochemistry at the iron L2,3 edge in [Fe(phen)2(NCS)2] and [Fe(phen)2(NCSe)2] (phen =1,10-phenanthroline). J. Chem. Soc. Dalton Trans. 1997, 4371-4376. [CrossRef]

8. Boča, R. Theoretical Foundations of Molecular Magnetism; Elsevier: Amsterdam, The Netherlands, 1999; ISBN: 9780080542713.

9. Kershaw Cook, L.J.; Kulmaczewski, R.; Mohammed, R.; Dudley, S.; Barrett, S.A.; Little, M.A.; Deeth, R.J.; Halcrow, M.A. A Unified Treatment of the Relationship Between Ligand Substituents and Spin State in a Family of Iron(II) Complexes. Angew. Chem. Int. Ed. 2016, 55, 4327-4331. [CrossRef] [PubMed]

10. Kershaw Cook, L.J.; Mohammed, R.; Sherborne, G.; Roberts, T.D.; Alvarez, S.; Halcrow, M.A. Spin state behavior of iron(II)/dipyrazolylpyridine complexes. New insights from crystallographic and solution measurements. Coor. Chem. Rev. 2015, 289-290, 2-12. [CrossRef]

11. Halcrow, M.A. Structure:function relationships in molecular spin-crossover complexes. Chem. Soc. Rev. 2011, 40, 4119-4142. [CrossRef] [PubMed]

12. Nemec, I.; Herchel, R.; Trávníček, Z. The relationship between the strength of hydrogen bonding and spin crossover behaviour in a series of iron(III) Schiff base complexes. Dalton Trans. 2015, 44, 4474-4484. [CrossRef] [PubMed]

13. Kahn, O.; Kröber, J.; Jay, C. Spin Transition Molecular Materials for displays and data recording. Adv. Mater. 1992, 4, 718-728. [CrossRef]

14. Krober, J.; Codjovi, E.; Kahn, O.; Grolibre, F.; Jay, C. A spin transition system with a thermal hysteresis at room temperature. J. Am. Chem. Soc. 1993, 115, 9810-9811. [CrossRef]

15. Niel, V.; Martinez-Agudo, J.M.; Carmen Munoz, M.; Gaspar, A.B.; Real, J.A. Cooperative Spin Crossover Behavior in Cyanide-Bridged Fe(II)-M(II) Bimetallic 3D Hofmann-like Networks ( $\mathrm{M}=\mathrm{Ni}, \mathrm{Pd}$, and $\mathrm{Pt})$. Inorg. Chem. 2001, 40, 3838-3839. [CrossRef] [PubMed]

16. Lemercier, G.; Bréfuel, N.; Shova, S.; Wolny, J.A.; Dahan, F.; Verelst, M.; Paulsen, H.; Trautwein, A.X.; Tuchagues, J.P. A Range of Spin-Crossover Temperature T1/2>300 K Results from Out-of-Sphere Anion Exchange in a Series of Ferrous Materials Based on the 4-(4-Imidazolylmethyl)-2-(2-imidazolylmethyl)imidazole (trim) Ligand, [Fe(trim)2]X2 ( $\mathrm{X}=\mathrm{F}, \mathrm{Cl}, \mathrm{Br}$, I): Comparison of Experimental Results with Those Derived from Density Functional Theory Calculations. Chem. Eur. J. 2006, 12, 7421-7432. [CrossRef] [PubMed]

17. Kuzu, I.; Krummenacher, I.; Hewitt, I.J.; Lan, Y.; Mereacre, V.; Powell, A.K.; Höfer, P.; Harmer, J.; Breher, F. Syntheses, Structures and Electronic Properties of Zwitterionic Iron(II) and Cobalt(II) Complexes Featuring Ambidentate Tris(pyrazolyl)methanide Ligands. Chem. Eur. J. 2009, 15, 4350-4365. [CrossRef] [PubMed]

18. Shatruk, M.; Dragulescu-Andrasi, A.; Kristen, E.; Chambers, K.E.; Stoian, S.A.; Bominaar, E.L.; Achim, C.; Dunbar, K.R. Properties of Prussian Blue Materials Manifested in Molecular Complexes: Observation of Cyanide Linkage Isomerism and Spin-Crossover Behavior in Pentanuclear Cyanide Clusters. J. Am. Chem. Soc. 2007, 129, 6104-6116. [CrossRef] [PubMed]

19. Min, K.S.; DiPasquale, A.; Arnold, L.; Rheingold, A.L.; Miller, J.S. Room-Temperature Spin Crossover Observed for [(TPyA)FeII(DBQ2-)FeII(TPyA)]2 + [TPyA = Tris(2-pyridylmethyl)amine; DBQ2- = 2,5-Di-tert-butyl-3,6-dihydroxy-1,4-benzoquinonate]. Inorg. Chem. 2007, 46, 1048-1050. [CrossRef] [PubMed] 
20. Nihei, M.; Ui, M.; Yokota, M.; Han, L.; Maeda, A.; Kishida, H.; Okamoto, H.; Oshio, H. Two-Step Spin Conversion in a Cyanide-Bridged Ferrous Square. Angew. Chem. Int. Ed. 2005, 44, 6484-6487. [CrossRef] [PubMed]

21. Šalitroš., I.; Madhu, N.T.; Boča, R.; Pavlik, J.; Ruben, M. Room-temperature spin-transition iron compounds. Monatsh. Chem. 2009, 140, 695-733. [CrossRef]

22. Kilner, C.A.; Halcrow, M.A. An iron(II) complex of 2,6-di(pyrazol-1-yl)pyrazine that crystallises in three forms, two of which exhibit an unusual angular Jahn-Teller distortion. Polyhedron 2006, 25, 235-240. [CrossRef]

23. Chandrasekar, R.; Schramm, F.; Fuhr, O.; Ruben, M. An Iron(II) Spin-Transition Compound with Thiol Anchoring Groups. Eur. J. Inorg. Chem. 2008, 2649-2653. [CrossRef]

24. Madhu, N.T.; Salitros, I.; Schramm, F.; Klyatskaya, S.; Fuhr, O.; Ruben, M. Above room temperature spin transition in a series of iron(II) bis(pyrazolyl)pyridine compounds. Compte Rendus Chim. 2008, 11, 1166. [CrossRef]

25. Šalitroš, I.; Fuhr, O.; Eichhöfer, A.; Kruk, R.; Pavlik, J.; Dlháň, L.; Boča, R.; Ruben, M. The interplay of iron(II) spin transition and polymorphism. Dalton Trans. 2012, 41, 5163-5171. [CrossRef]

26. Šalitroš, I.; Pogány, L.; Ruben, M.; Boča, R.; Linert, W. Polymorphism dependent light induced spin transition. Dalton Trans. 2014, 43, 16584-16587. [CrossRef] [PubMed]

27. Pritchard, R.; Lazar, H.; Barrett, S.A.; Kilner, C.A.; Asthana, S.; Carbonera, C.; Létard, J.-F.; Halcrow, M.A. Thermal and light-induced spin-transitions in iron(II) complexes of 2,6-bis(4-halopyrazolyl)pyridines: The influence of polymorphism on a spin-crossover compound. Dalton Trans. 2009, 6656-6666. [CrossRef] [PubMed]

28. Cavallini, M.; Bergenti, I.; Milita, S.; Kengne, J.C.; Gentili, D.; Ruani, G.; Salitros, I.; Meded, V.; Ruben, M. Thin Deposits and Patterning of Room-Temperature-Switchable One-Dimensional Spin-Crossover Compounds. Langmuir 2011, 27, 4076-4081. [CrossRef] [PubMed]

29. Devid, E.J.; Martinho, P.N.; Kamalakar, M.V.; Salitros, I.; Prendergast, U.; Dayen, J.-F.; Meded, V.; Lemma, T.; González-Prieto, R.; Evers, F.; et al. Spin Transition in Arrays of Gold Nanoparticles and Spin Crossover Molecules. ACS Nano 2015, 9, 4496-4507. [CrossRef] [PubMed]

30. Naik, A.D.; Tinant, B.; Muffler, K.; Wolny, J.A.; Schunemann, V.; Garcia, Y. Relevance of supramolecular interactions, texture and lattice occupancy in the designer iron(II) spin crossover complexes. J. Solid State Chem. 2009, 182, 1365-1376. [CrossRef]

31. Šalitroš, I.; Pavlik, J.; Boča, R.; Fuhr, O.; Rajadurai, C.; Ruben, M. Supramolecular lattice-solvent control of iron(II) spin transition parameters. Cryst. Eng. Commun. 2010, 12, 2361-2368. [CrossRef]

32. Rajadurai, C.; Qu, Z.; Fuhr, O.; Gopalan, B.; Kruk, R.; Ghafari, M.; Ruben, M. Lattice-solvent controlled spin transitions in iron(II) complexes. Dalton Trans. 2007, 3531-3537. [CrossRef] [PubMed]

33. Kershaw Cook, L.J.; Shepherd, H.J.; Comyn, T.P.; Baldé, C.; Cespedes, O.; Chastanet, G.; Halcrow, M.A. Decoupled Spin Crossover and Structural Phase Transition in a Molecular Iron(II) Complex. Angew. Chem. Int. Ed. 2015, 21, 4805-4816. [CrossRef] [PubMed]

34. $\sum=\sum_{i=1}^{12}\left(\left|\varphi_{i}-90\right|\right)$; where $\phi_{i}$ is value of $\mathrm{N}-\mathrm{Fe}-\mathrm{N}$ octahedron angle.

35. Guionneau, P.; Marchivie, M.; Bravic, G.; Létard, J.F.; Chasseau, D.; Ksenofontov, V.; Gaspar, A.B.; Gütlich, P. Structural Aspects of Spin Crossover. Example of the [FeIILn(NCS)2] Complexes. In Spin Crossover in Transition Metal Compounds II; Gütlich, P., Goodwin, H.A., Eds.; Springer-Verlag: Berlin/Heidelberg, Germany, 2004; ISSN: 0340-1022.

36. Desiraju, G.R.; Steiner, T. The Weak Hydrogen Bond; IUCr Oxford Science Publication: Oxford, UK, 1999; ISBN: 9780198509707.

37. Sheldrick, G.M. Phase Annealing in SHELX-90: Direct Methods for Larger Structures. Acta Crystallogr. Sect. A 1990, 660, 467-473. [CrossRef]

38. Sheldrick, G.M. SHELXL-97 (Release 97-2) Program for the refinement of Crystal Structures; University of Göttingen: Göttingen, Germany, 1997.

(C) 2016 by the authors; licensee MDPI, Basel, Switzerland. This article is an open access article distributed under the terms and conditions of the Creative Commons Attribution (CC-BY) license (http://creativecommons.org/licenses/by/4.0/). 